\title{
Biochemical and spectroscopic characterization of the membrane-bound nitrate reductase from Marinobacter hydrocarbonoclasticus 617
}

\author{
Cristina Correia · Stéphane Besson · Carlos D. Brondino · Pablo J. González • \\ Guy Fauque · Jorge Lampreia · Isabel Moura · José J. G. Moura
}

Received: 21 June 2008/ Accepted: 2 August 2008/Published online: 14 August 2008

(C) SBIC 2008

\begin{abstract}
Membrane-bound nitrate reductase from Marinobacter hydrocarbonoclasticus 617 can be solubilized in either of two ways that will ultimately determine the presence or absence of the small (I) subunit. The enzyme complex (NarGHI) is composed of three subunits with molecular masses of 130,65 , and $20 \mathrm{kDa}$. This enzyme contains approximately $14 \mathrm{Fe}, 0.8 \mathrm{Mo}$, and 1.3 molybdopterin guanine dinucleotides per enzyme molecule. Curiously, one heme $b$ and 0.4 heme $c$ per enzyme molecule have been detected. These hemes were potentiometrically characterized by optical spectroscopy at $\mathrm{pH}$ 7.6 and two noninteracting species were identified with respective midpoint potentials at $E_{\mathrm{m}}=+197 \mathrm{mV}$ (heme $c$ ) and $-4.5 \mathrm{mV}$ (heme $b$ ). Variable-temperature (4-120 K) $\mathrm{X}$-band electron paramagnetic resonance (EPR) studies
\end{abstract}

Electronic supplementary material The online version of this article (doi:10.1007/s00775-008-0416-1) contains supplementary material, which is available to authorized users.

C. Correia · S. Besson · P. J. González · J. Lampreia ·

I. Moura · J. J. G. Moura $(\bowtie)$

REQUIMTE/CQFB, Departamento de Química,

Faculdade de Ciências e Tecnologia

da Universidade Nova de Lisboa,

2829-516 Caparica, Portugal

e-mail: jose.moura@dq.fct.unl.pt

\section{S. Besson}

UIBD, Faculdade de Engenharias e Ciências Naturais, Universidade Lusófona de Humanidades e Tecnologias,

Campo Grande 376, 1749-024 Lisbon, Portugal

\section{D. Brondino $(\square)$}

Facultad de Bioquímica y Ciencias Biológicas,

Universidad Nacional del Litoral,

3000 Santa Fe, Argentina

e-mail: brondino@fbcb.unl.edu.ar performed on both as-isolated and dithionite-reduced nitrate reductase showed, respectively, an EPR signal characteristic of a $[3 \mathrm{Fe}-4 \mathrm{~S}]^{+}$cluster and overlapping signals associated with at least three types of $[4 \mathrm{Fe}-4 \mathrm{~S}]^{+}$ centers. EPR of the as-isolated enzyme shows two distinct $\mathrm{pH}$-dependent $\mathrm{Mo}(\mathrm{V})$ signals with hyperfine coupling to a solvent-exchangeable proton. These signals, called "low$\mathrm{pH}$ " and "high-pH," changed to a $\mathrm{pH}$-independent $\mathrm{Mo}(\mathrm{V})$ signal upon nitrate or nitrite addition. Nitrate addition to dithionite-reduced samples at $\mathrm{pH} 6$ and 7.6 yields some of the EPR signals described above and a new rhombic signal that has no hyperfine structure. The relationship between the distinct EPR-active $\mathrm{Mo}(\mathrm{V})$ species and their plausible structures is discussed on the basis of the structural information available to date for closely related membranebound nitrate reductases.

\section{G. Fauque}

Laboratoire de Microbiologie,

Institut de Recherche Pour le Développement,

UR 101, IFR-BAIM,

Universités de Provence et de la Méditerranée, ESIL,

Case 925, 163 Avenue de Luminy,

13288 Marseille Cedex 9, France

\section{G. Fauque}

Laboratoire de Microbiologie,

Géochimie et Ecologie Marines,

CNRS UMR 6117,

Campus de Luminy, Case 901,

13288 Marseille Cedex 09, France 
Keywords Nitrate reductase - Electron paramagnetic resonance $\cdot$ Molybdenum · Denitrification .

Marinobacter hydrocarbonoclasticus

$\begin{array}{ll}\begin{array}{l}\text { Abbreviations } \\ \text { Bis-Tris }\end{array} & \begin{array}{l}\text { [Bis(2-hydroxyethyl)imino]tris } \\ \text { (hydroxymethyl)methane } \\ \text { Bis-Tris }\end{array} \\ \text { propane } & \begin{array}{l}\text { methylamino]propane } \\ n \text {-Dodecyl- } \beta \text {-D-maltoside }\end{array} \\ \text { DDM } & \text { Dimethyl sulfoxide } \\ \text { DMSO } & \text { Electron paramagnetic resonance } \\ \text { EPR } & \text { Molybdopterin guanine dinucleotide } \\ \text { MGD } & \text { Respiratory nitrate reductase } \\ \text { Nar } & \text { Phenethyl alcohol } \\ \text { PA } & \text { Polyacrylamide gel electrophoresis } \\ \text { PAGE } & \text { Sodium dodecyl sulfate } \\ \text { SDS } & \text { Tris(hydroxymethyl)aminomethane } \\ \text { Tris-HCl } & \text { hydrochloride }\end{array}$

\section{Introduction}

Organisms reduce nitrate for three main reasons: to incorporate nitrogen into biomolecules (assimilation), to generate energy for cellular function (respiration), and to dissipate the excess reducing power generated by the metabolism [1-6]. Nitrate reductases catalyze the reduction of nitrate to nitrite according to the reaction

$\mathrm{NO}_{3}^{-}+2 \mathrm{H}^{+}+2 e^{-} \rightarrow \mathrm{NO}_{2}^{-}+\mathrm{H}_{2} \mathrm{O} \quad E^{0}=420 \mathrm{mV}$.

This reaction can be catalyzed by different enzymes that can be grouped according to their function, localization in the cell, structure, and the metabolic route in which they participate [6]. With the exception of the eukaryotic nitrate reductases, which are part of the sulfite oxidase family, all the prokaryotic nitrate reductases belong to the dimethyl sulfoxide (DMSO) reductase family of Mo-containing enzymes [7]. The respiratory nitrate reduction pathway involves the membrane-bound respiratory nitrate reductase (Nar), which has been isolated from a variety of organisms, including a few well-studied bacteria [8-14]. Nars are involved in the redox loop generating the proton motive force across biomembranes [15]. These proteins are constituted by three subunits: NarG, NarH, and NarI. NarG contains the active site of the enzyme, whereas the remaining subunits contain electron transfer centers. The NarGH complex is located in the cytoplasm but remains anchored to the inner surface of the cytoplasmic membrane by the transmembrane NarI subunit. Nars can be purified with or without the NarI subunit, depending on the purification procedure.
The crystal structures of NarGHI and NarGH from Escherichia coli, solved at a resolution of $1.9 \AA$ [16] and $2.0 \AA$ [17], respectively, showed that the catalytic NarG subunit $(118-150 \mathrm{kDa})$ contains the molybdenum site and one $[4 \mathrm{Fe}-4 \mathrm{~S}]$ cluster (FSO), the NarH subunit (55-64 kDa) contains one [3Fe-4S] cluster (FS4) and three [4Fe-4S] clusters (FS1, FS2, and FS3), and the NarI subunit (19-26 kDa) contains two $b$-type hemes $\left(b_{\mathrm{P}}\right.$ and $\left.b_{\mathrm{D}}\right)$. All the redox cofactors are located along an electron transfer pathway $\left(b_{\mathrm{D}}-b_{\mathrm{P}}-\mathrm{FS}_{4}-\mathrm{FS}_{3}-\mathrm{FS}_{2}-\mathrm{FS}_{1}-\mathrm{FS}_{0}-\mathrm{Mo}\right)$ from which the nitrate receives the electrons provided by the quinol pool [15]. The three-dimensional structure also revealed features never observed before in the active site of proteins of the DMSO reductase family. Both structures show a distorted hexacoordinated active site with the molybdenum atom coordinated by four sulfur atoms from two molybdopterin guanine dinucleotide (MGD) cofactors, as usually observed in this enzyme family, and the side chain carboxylate of an aspartate residue (Structure 1). This aspartate molecule has bidentate coordination in NarGHI [16] but monodentate coordination in NarGH, with the sixth coordination position being occupied by an oxo group ( $\mathrm{Mo}=\mathrm{O}$ bond distance approximately $1.8 \AA$ ) [17] absent in the NarGHI structure. In both cases the crystals were grown aerobically and therefore both structures should represent the oxidized form of the enzyme.

The redox and electron paramagnetic resonance (EPR) properties of the active site of membrane-bound nitrate reductases obtained from different sources have been the subject of several studies [9, 18-20]. Nars show $\mathrm{pH}$-dependent $\mathrm{Mo}(\mathrm{V})$ ion EPR signals with resonances split by a solvent-exchangeable proton. The EPR-active species are identified as "low-pH" $\quad\left(g_{1}=2.001\right.$, $\left.g_{2}=1.986, g_{3}=1.964, A_{\mathrm{av}}=9.6 \mathrm{G}\right)$ and "high-pH" ( $\left.g_{1}=1.987, g_{2}=1.981, g_{3}=1.962, A_{\mathrm{av}}=3.4 \mathrm{G}\right)$ [19]. The catalytic significance of these two distinct Mo(V) EPR species has been intensively discussed. On the basis of the activity profile, Vincent and Bray [18] have suggested that only the low-pH $\mathrm{Mo}(\mathrm{V})$ form is catalytically active, while Magalon et al. [21], upon determining midpoint redox potentials for the high-pH and low-pH forms, defended the

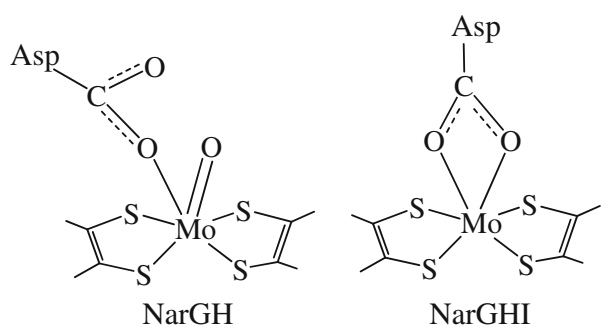

Structure 1 
claim that both forms should be involved in the enzyme turnover. The EPR properties of the iron-sulfur cluster centers have also been extensively studied [21-24]. Nar from $E$. coli shows the typical EPR resonances of the $[3 \mathrm{Fe}-$ $4 \mathrm{~S}]^{+}$and $[4 \mathrm{Fe}-4 \mathrm{~S}]^{+}$centers in low-spin configuration, which were assigned to the clusters of the $\beta$-subunit [23]. More recently, it was confirmed that the $[4 \mathrm{Fe}-4 \mathrm{~S}]^{+}$center of the NarG subunit has a high-spin $(S=3 / 2)$ ground-state configuration [25].

In denitrifiers such as Marinobacter hydrocarbonoclasticus 617 (formerly known as Pseudomonas nautica 617), Nar initiates a complete denitrification pathway that involves three other enzymes responsible for the further reduction of nitrite, via nitric oxide and nitrous oxide, to dinitrogen. The purification and characterization of nitrite reductase (cytochrome $c d_{1}$ ) [26], NO reductase [27], and $\mathrm{N}_{2} \mathrm{O}$ reductase [28] from $M$. hydrocarbonoclasticus 617 have provided insight into the denitrifying system of this bacterium. The investigation of the enzyme involved in the first step of the denitrification pathway is therefore important to learn more about this particular respiratory system. We report here the purification and biochemical and spectroscopic characterization of the membrane-bound nitrate reductase isolated from the marine denitrifier $M$. hydrocarbonoclasticus 617 . We also discuss the relationships between the distinct Mo(V) species detected by EPR and their plausible structures on the basis of the structural information available to date for membrane-bound nitrate reductases.

\section{Materials and methods}

Growth of M. hydrocarbonoclasticus 617

and membrane isolation

M. hydrocarbonoclasticus 617 was grown under denitrifying conditions in artificial seawater at $303 \mathrm{~K}$ with $10 \mathrm{mM}$ nitrate as an electron acceptor [29]. Yeast extract $(0.1 \%)$ and lactate $(1 \%)$ were used as carbon and energy sources and the medium was supplemented with a separately sterilized Starkey oligoelement solution $(0.2 \mathrm{~mL} / \mathrm{L}$ of culture) [30]. A final $300 \mathrm{~L}$ growth volume corresponding to $250 \mathrm{~g}$ wet weight cells was obtained in the Unité de Fermentation at LCB-CNRS, Marseille, France. Cells were harvested in the late exponential phase of growth by centrifugation, resuspended in $100 \mathrm{mM}$ tris(hydroxymethyl)aminomethane hydrochloride (Tris$\mathrm{HCl}) \mathrm{pH} 7.0$, and broken in a French press. The crude extract was centrifuged at $8,000 \mathrm{~g}$ for $20 \mathrm{~min}$ to remove cell debris, and twice at $125,000 \mathrm{~g}$ for $1 \mathrm{~h}$ to separate membrane and soluble fractions.

\section{Purification of the heat-solubilized NarGH}

Apart from the initial solubilization step, all the purification procedures were performed aerobically at $277 \mathrm{~K}$. The membrane fraction was subjected to heat treatment in a water bath $(60 \mathrm{~min}$ at $333 \mathrm{~K}$ ) under an argon atmosphere with slight stirring. The mixture was centrifuged at $175,000 \mathrm{~g}$ for $120 \mathrm{~min}$ at $277 \mathrm{~K}$. The supernatant was loaded onto an ion-exchange (diethylamino)ethyl cellulose column $(4.5 \mathrm{~cm} \times 40 \mathrm{~cm})$ equilibrated with $10 \mathrm{mM}$ Tris$\mathrm{HCl} \mathrm{pH} \mathrm{7.6.} \mathrm{A} \mathrm{linear} \mathrm{gradient}(10-500 \mathrm{mM})$ of Tris- $\mathrm{HCl}$ pH 7.6 was applied with a total volume of 2 L. The maximum activity was found in the fraction eluted at $250 \mathrm{mM}$. This fraction was then dialyzed against $10 \mathrm{mM}$ Tris- $\mathrm{HCl}$ buffer pH 7.6 and applied to an anion-exchange column (Source 15, Pharmacia, $2.7 \mathrm{~cm} \times 20 \mathrm{~cm}$ ). The proteins were eluted using a Tris- $\mathrm{HCl}$ pH 7 buffer gradient (10$500 \mathrm{mM}$ ) and the main fraction that contained Nar activity was collected at $300 \mathrm{mM}$ Tris- $\mathrm{HCl}$. Ionic strength was decreased in the fraction by adding Millipore water. The final step was a gel-filtration column (Superdex $200 \mathrm{HR} 10$ / 30, Pharmacia, $1.0 \mathrm{~cm} \times 30 \mathrm{~cm}$ ) equilibrated with $300 \mathrm{mM}$ Tris- $\mathrm{HCl}$ buffer $\mathrm{pH}$ 7.6. The purified enzyme was concentrated and stored at $203 \mathrm{~K}$.

\section{Purification of the detergent-solubilized NarGHI}

The membrane fraction was washed in a buffer containing $50 \mathrm{mM}$ Tris- $\mathrm{HCl} \mathrm{pH} 8.0$ and centrifuged at 175,000g for $90 \mathrm{~min}$ at $277 \mathrm{~K}$. The pellet was resuspended in a buffer containing $150 \mathrm{mM} \mathrm{KCl}$ and $50 \mathrm{mM}$ Tris- $\mathrm{HCl} \mathrm{pH} 8.0$ to reach a protein concentration of $10 \mathrm{mg} / \mathrm{mL}$. The membranes were then centrifuged twice more as described already. Finally, they were suspended in $50 \mathrm{mM}$ Tris- $\mathrm{HCl}$ pH 8.0 buffer with $150 \mathrm{mM} \mathrm{KCl}$ and $0.02 \%$ (v/v) phenethyl alcohol (PA; Sigma) to obtain a protein concentration of $10 \mathrm{mg} / \mathrm{mL}$. Afterwards, the membranes were cooled on ice and the detergent $n$-dodecyl- $\beta$-Dmaltoside (DDM; Calbiochem) was added to a final concentration of $0.9 \%(\mathrm{w} / \mathrm{v})$. The mixture was stirred for $45 \mathrm{~min}$ and centrifuged at $175,000 \mathrm{~g}$ for $60 \mathrm{~min}$ at $277 \mathrm{~K}$. The supernatant was loaded onto a $270 \mathrm{~mL}$ (diethylamino)ethyl Sepharose (Pharmacia) column washed (2 times column volume) and equilibrated with $50 \mathrm{mM}$ Tris- $\mathrm{HCl} \mathrm{pH} 8.0$ buffer with $0.02 \%$ (v/v) PA and $0.04 \%$ (w/v) DDM. A $0-500 \mathrm{mM}$ linear gradient of $\mathrm{NaCl}$ in $50 \mathrm{mM}$ Tris-HCl pH 8.0 buffer was used for elution (5 times column volume). Pooled fractions with Nar activity were concentrated (and ionic strength was lowered) in a Diaflo system (Amicon, 30-kDa pore size membrane) and then applied to a $165 \mathrm{~mL}$ DEAESepharose Fast Flow column (Pharmacia) equilibrated 
with $10 \mathrm{mM}$ Tris- $\mathrm{HCl} \mathrm{pH} 7.6$ buffer containing $0.01 \%$ $(\mathrm{v} / \mathrm{v}) \mathrm{PA}$ and $0.03 \%(\mathrm{w} / \mathrm{v})$ DDM. A nonlinear gradient of 10-500 mM in Tris- $\mathrm{HCl} \mathrm{pH} 7.6$ buffer with $0.01 \%(\mathrm{v} / \mathrm{v})$ PA and $0.03 \%(w / v)$ DDM was used and the protein was eluted at $400 \mathrm{mM}$. The final chromatographic step was performed using a Superdex 200 HR10/30 gel-filtration column (Pharmacia, $1.0 \times 30 \mathrm{~cm}$ ) equilibrated with $300 \mathrm{mM}$ Tris- $\mathrm{HCl} \mathrm{pH} 8.0$ buffer with $0.01 \%$ (v/v) PA and $0.08 \%(\mathrm{w} / \mathrm{v})$ DDM. The purified enzyme was dialyzed and concentrated in $10 \mathrm{mM}$ Tris- $\mathrm{HCl} \mathrm{pH} 8.0$ buffer with $0.01 \%(\mathrm{v} / \mathrm{v}) \mathrm{PA}$ and $0.03 \%(\mathrm{v} / \mathrm{v}) \mathrm{DDM}$ and stored at $203 \mathrm{~K}$.

\section{Gel electrophoreses}

Sodium dodecyl sulfate (SDS) polyacrylamide gel electrophoresis (PAGE; $12.5 \%$ polyacrylamide) and native PAGE (10\% polyacrylamide) were performed with Laemmli's discontinuous buffer system [31]. For SDS-PAGE the samples were previously heated at $313 \mathrm{~K}$ for $30 \mathrm{~min}$.

Activity and heme peroxidatic activity staining

A method for nitrite reductase activity staining [32] was modified to detect Nar activity in native gels. The electrophoresis was performed and then the gel was placed under an argon atmosphere in a buffer containing $50 \mathrm{mM}$ phosphate $\mathrm{pH} 8.0,0.96 \mathrm{mg} / \mathrm{mL}$ methyl viologen, and $1 \mathrm{mg} /$ $\mathrm{mL} \mathrm{NaNO}_{3}$. About $3 \mathrm{~mL}$ of sodium dithionite $(40 \mathrm{mg} / \mathrm{mL}$ in $0.1 \mathrm{M} \mathrm{NaHCO}_{3}$ ) was added and the reaction proceeded until discoloration bands corresponding to Nar activity were detected. Afterwards, a solution of $2.5 \%(\mathrm{w} / \mathrm{v})$ triphenyltetrazolium chloride was used to achieve a permanent staining. A $50 \%$ (v/v) ethanol solution was used to fix the color. Heme staining was performed as described by Goodhew et al. [33].

\section{Enzymatic assay}

Conversion of nitrate to nitrite was performed following the oxidation of the artificial electron donor methyl viologen at $604 \mathrm{~nm}\left(\varepsilon_{604}=13.6 \mathrm{mM}^{-1} \mathrm{~cm}^{-1}\right.$, Sigma $)$ using an HP 8452A diode-array spectrophotometer. The reaction was started by the addition of nitrate. The assay mixture, total volume $2.0 \mathrm{~mL}$, contained $0.4 \mathrm{mM}$ methyl viologen, $0.5 \mathrm{mM}$ dithionite, and $20 \mathrm{mM}$ nitrate. Nar activity is expressed in micromoles of nitrate reduced per minute per milligram of enzyme (U/mg). All the activity assays were performed anaerobically. Alternatively, nitrate reductase activity was measured by diazotization and coupling reactions [34] using methyl viologen as the electron donor.

\section{Protein determination}

Protein concentration was determined by the bicinchoninic acid method (Pierce) [35]. Bovine serum albumin (Pierce) was used as a standard.

UV-vis spectroscopy

UV-vis absorption spectra were recorded with either a Shimadzu UV-2101 PC or a Shimadzu UV-265 FS splitbeam spectrophotometer using $1-\mathrm{cm}$ quartz cells.

Molecular mass determination

The molecular masses of the purified denatured subunits were determined by SDS-PAGE (12.5\% polyacrylamide) against low molecular mass markers (Amersham Biosciences): phosphorylase b (97 kDa), bovine serum albumin (66 kDa), ovalbumin (45 kDa), carbonic anhydrase (30 kDa), trypsin inhibitor $(20.1 \mathrm{kDa})$, and $\alpha$-lactalbumin $(14.4 \mathrm{kDa})$. The molecular mass of the as-isolated protein was estimated by gel-filtration chromatography. A prepacked Superdex 200 HR 10/30 column (Pharmacia) connected to a high performance liquid chromatography device (LC 10AD and SPD, Shimadzu) was equilibrated with $300 \mathrm{mM}$ Tris- $\mathrm{HCl}$ pH 7.6 buffer with $0.2 \%$ (v/v) Tween 80 . Isocratic elution at a flow rate of $0.4 \mathrm{~mL} / \mathrm{min}$ was performed with detection at $280 \mathrm{~nm}$. High molecular mass markers (Pharmacia) were used for calibration. The size markers were thyroglobulin (669 kDa), ferritin (440 kDa), $\beta$-amylase (200 kDa), alcohol dehydrogenase $(150 \mathrm{kDa})$, and bovine serum albumin (66 kDa).

\section{Redox titrations}

Experiments were carried out at room temperature under a prehumidified argon atmosphere. The total assay volume of $3.0 \mathrm{~mL}$ contained $50 \mathrm{mM}$ Tris- $\mathrm{HCl} \mathrm{pH} 7.6$ buffer with $0.03 \%(\mathrm{w} / \mathrm{v}) \mathrm{DDM}$ and the final protein concentration was $2.8 \mathrm{mg} / \mathrm{mL}$. The mediators (5 $\mu \mathrm{M}$ each) were 1,2-naphthoquinone, 1,4-naphthoquinone, phenazine methosulfate, phenazine ethosulfate, methylene blue, phenosafranin, phenazine, 2 hydroxy-1,4-naphthoquinone, duroquinone, 1,2-naphthoquinone-4-sulfonic acid, and 2,6-dichlorophenol-indophenol. Dithionite and ascorbate were used as reductants and ferricyanide was used as the oxidant. Optical data were collected using a Shimadzu UV-2101 spectrophotometer in the range 400-750 $\mathrm{nm}$. Baseline and dilution corrections were performed and absorbance at $558 \mathrm{~nm}$ was followed. The cell was calibrated with saturated quinhydrone solution at $\mathrm{pH}$ 7.0. Potentials were measured with a Crison micro $\mathrm{pH} 2002$ potentiometer using platinum and $\mathrm{Ag} / \mathrm{AgCl} \mathrm{KCl}(3 \mathrm{M})$ electrodes. Values 
are expressed relative to the redox potential of the standard normal hydrogen electrode.

Heme $b$ extraction, apoprotein preparation, and heme quantification

The extraction of heme $b$ was accomplished using acidic acetone $(0.015 \mathrm{M} \mathrm{HCl})$ on ice and in the absence of light. After $1 \mathrm{~min}$ of vigorous agitation and $2 \mathrm{~min}$ of centrifugation at $2,700 \mathrm{~g}$ the supernatant was removed. The procedure was repeated twice. The heme-containing supernatant was dried in a speed-vacuum system (Braun) and resuspended in $25 \mathrm{mM}$ Tris- $\mathrm{HCl}$ buffer $\mathrm{pH}$ 8.5. The precipitate was resuspended in $25 \mathrm{mM}$ phosphate buffer pH 9.0 containing $0.1 \%$ (v/v) Tween 80 . The heme content was determined by the pyridine hemochromogen method using extinction coefficients of $34.4 \mathrm{mM}^{-1} \mathrm{~cm}^{-1}$ (at $557 \mathrm{~nm}$ ) and $29.1 \mathrm{mM}^{-1} \mathrm{~cm}^{-1}$ (at $551 \mathrm{~nm}$ ) for heme $b$ and heme $c$, respectively $[36,37]$.

Metal analysis

Iron and molybdenum contents were determined by inductively coupled plasma emission analysis (Jobin-Yvon Ultima) on protein samples in $10 \mathrm{mM}$ Tris- $\mathrm{HCl} \mathrm{pH} 7.6$ and $0.02 \%(\mathrm{w} / \mathrm{v})$ DDM. Iron content was also measured through the complex formation of $\mathrm{Fe}(\mathrm{II})$ with 2,4,6-tripyridyl-s-triazine as described by Fisher and Price [38]. The free iron standard solution was obtained from Sigma.

\section{Analysis of mononucleotides}

The molybdopterin extraction was mainly performed according to the method described by Kretzer et al. [39] and Gremer and Meyer [40]. The pterin was extracted from a dialyzed protein sample with concentrated $\mathrm{H}_{2} \mathrm{SO}_{4}$ in a $3 \%(\mathrm{v} / \mathrm{v})$ proportion. It was heated to $368 \mathrm{~K}$ for $10 \mathrm{~min}$ and centrifuged at $18,000 \mathrm{~g}$ for $10 \mathrm{~min}$. The supernatant was applied to a Supersher100 RP-18 end-capped column (Merck) connected to a high performance liquid chromatography device (L-7400, D-7000 and L-7100, Merck) equilibrated with $50 \mathrm{mM}$ ammonium acetate $\mathrm{pH} 6.8$ buffer. Isocratic elution with the same buffer was performed at a flow rate of $1.0 \mathrm{~mL} / \mathrm{min}$ with detection at $254 \mathrm{~nm}$. Quantitative measurements were achieved by injecting known amounts of freshly prepared solutions of standard nucleotides (CMP and GMP, Sigma) subjected to the same treatment.

\section{EPR spectroscopy}

X-band EPR spectra were recorded using a Bruker EMX spectrometer equipped with a rectangular cavity (model ER
4102ST) and an Oxford Instruments continuous-flow cryostat. EPR spectra were simulated using the program WINEPR Simfonia version 1.2. from Bruker Instruments. Spin quantification was performed at the same temperature under nonsaturating conditions, using $3 \mathrm{mM}$ cupric EDTA as a standard. Samples for EPR spectroscopy were prepared with $150 \mu \mathrm{M}$ enzyme in $50 \mathrm{mM}$ [bis(2-hydroxyethyl)imino]tris(hydroxymethyl)methane (Bis-Tris) with $0.02 \%$ DDM). 1,3-Bis[tris(hydroxymethyl)methylamino] propane (Bis-Tris propane) buffer (Sigma) was used in the EPR studies of the Mo(V) ion $\mathrm{pH}$ transition. No significant differences between EPR spectra recorded at $\mathrm{pH} 7.6$ in Tris- $\mathrm{HCl}$ and Bis-Tris propane buffers were observed. Experimental conditions are described in the figure legends.

Reoxidation experiments with nitrate were performed in the following way. Before nitrate addition, samples were reduced with dithionite (approximately 50-fold molar excess), incubated for approximately $30 \mathrm{~min}$ under an argon atmosphere, and then frozen in liquid nitrogen. The spectra were recorded immediately after nitrate addition and were then thawed and frozen every $3 \mathrm{~min}$ for $60 \mathrm{~min}$ with the EPR tube on ice, following nitrate addition (approximately 200-fold molar excess). Afterwards, the samples were first air-reoxidized and were then washed with Bis-Tris propane pH 6.0 or 7.6 buffer.

\section{Results}

Purification and biochemical characterization

Nitrate reductase activity has been previously detected in the membrane fraction of M. hydrocarbonoclasticus 617 [41]; thus, this fraction was used as protein source, from which both heat-solubilized NarGH and detergent-solubilized NarGHI forms of the enzyme were purified.

SDS-PAGE of the as-isolated NarGH shows two bands with respective molecular masses of 140 and $58 \mathrm{kDa}$ (Fig. 1, lane B). In a native PAGE a single band of purified NarGH was observed (Fig. 1, lane C) and this band exhibited nitrate reductase activity as demonstrated by activity staining (Fig. 1, lane D). The molecular masses of the subunits are similar to those determined for $\mathrm{NarGH}$ from E. coli [42], Paracoccus denitrificans [11], and Pseudomonas aeruginosa [43].

The detergent DDM was used in the solubilization of the NarGHI trimer, and the best yield was achieved with a ratio of $0.9 \mathrm{~g}$ DDM per milligram of protein. The SDS-PAGE of the detergent-solubilized Nar showed three bands corresponding to molecular masses of 136,65 , and $20 \mathrm{kDa}$ (Fig. 1, lane F). A native PAGE with staining for nitrate reductase activity showed a single band, with a high 


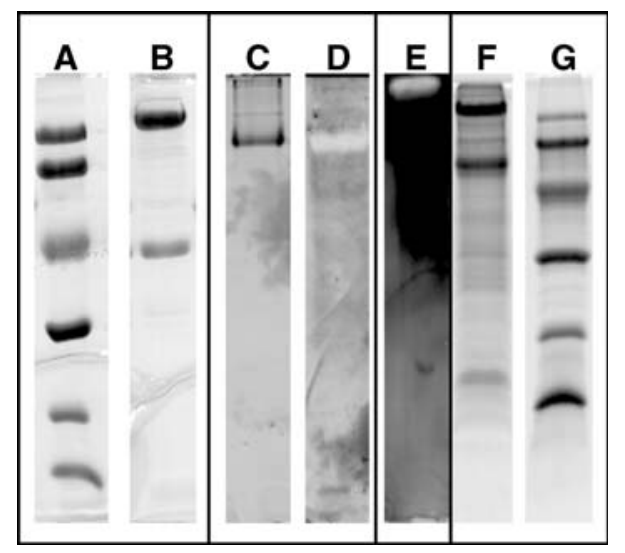

Fig. 1 Electrophoretic analysis of NarGH and NarGHI enzyme complexes isolated from Marinobacter hydrocarbonoclasticus 617: A and $G$ low molecular weight markers (Amersham Biosciences); $B$ NarGH, sodium dodecyl sulfate (SDS) polyacrylamide gel electrophoresis (PAGE; 10\%), stained with Coomassie Blue R-250: $C$ NarGH, native PAGE, stained with Coomassie blue R-250; $D$ NarGH, native PAGE, stained for respiratory nitrate reductase (Nar) activity; $E$ NarGHI, native PAGE; stained for Nar activity; $F$ NarGHI, SDS-PAGE (12.5\%), stained with Coomassie blue R-250

molecular mass (Fig. 1, lane E). Determination of NarGHI molecular mass by gel filtration yielded a value of $240 \mathrm{kDa}$, suggesting a stoichiometry of 1:1:1 as reported for closely related proteins. A minor component with a molecular mass of approximately $400 \mathrm{kDa}$ was also detected, suggesting that some form of aggregation may occur. This possibility was also supported by the presence of two nitrate reductase activity bands in another native PAGE ( $7.5 \%$ polyacrylamide), where the second band might correspond to a multimeric form of NarGHI (data not shown). A similar phenomenon was reported for the $E$. coli enzyme where aggregates up to $800 \mathrm{kDa}$ were detected $[8,44]$. The subunit stoichiometry and molecular masses are in agreement with the recently determined structure of the $E$. coli enzyme [16, 18].

$b$-type hemes have been previously detected in the NarI subunit of other bacterial membrane-bound nitrate reductases $[8,10,11]$. To detect their presence in M. hydrocarbonoclasticus 617 Nar, heme-dependent peroxidatic activity staining of native and denaturated forms of the enzyme was performed. The native PAGE showed a single stained band corresponding to the molecular mass of the NarGHI trimer. Surprisingly, the SDS-PAGE experiment showed a band that matches the molecular mass of the small subunit. This result suggests the presence of $c$-type heme(s) in M. hydrocarbonoclasticus $617 \mathrm{NarI}$ or in a contaminant of similar molecular mass, as the $b$-type hemes are not covalently bound to the protein and therefore peroxidatic activity staining should not be observed under these conditions.

Inductively coupled plasma mass spectrometry yielded a molybdenum content of $0.8 \mathrm{~mol} / \mathrm{mol}$ of NarGHI assuming a molecular mass of $240 \mathrm{kDa}$. Tungsten was not detected. Total iron was present at a concentration of $14.0 \pm$ $0.7 \mathrm{~mol} / \mathrm{mol}$ of protein. Pterin nucleotide analysis identified 1.3 MGDs per protein molecule. The MGD to molybdenum ratio is 1.6 , which confirms that two MGDs are coordinated to the molybdenum atom. The detergentsolubilized form of the enzyme showed a specific activity (NarGHI, $40 \mathrm{U} / \mathrm{mg}$ ) higher than that of the heat-solubilized enzyme (NarGH, $13 \mathrm{U} / \mathrm{mg}$ ). The kinetic parameters obtained with a Michaelis model for NarGHI were $K_{\mathrm{M}}=295 \mu \mathrm{M}$ and $V_{\mathrm{m}}=18 \mu \mathrm{M} / \mathrm{min}$. In contrast to what has been observed for the E. coli Nar [45], the activity versus $\mathrm{pH}$ profile of $M$. hydrocarbonoclasticus $617 \mathrm{Nar}$ shows that the activity is constant between $\mathrm{pH} 6$ and 8 , but drops significantly above $\mathrm{pH} 8$.

\section{UV-vis spectroscopy}

The UV-vis spectrum of oxidized $M$. hydrocarbonoclasticus 617 NarGH shows a broad shoulder around $410 \mathrm{~nm}$ characteristic of $\mathrm{FeS}$ centers and an $A_{280} / A_{410}$ purity ratio of 4.0 (Fig. 2a). By contrast, in the UV-vis spectrum of asisolated oxidized NarGHI, a heme moiety is detected at $410 \mathrm{~nm}$ (Soret band) (Fig. 2b, spectrum 1). Upon reduction with sodium ascorbate, this band shifts to $416 \mathrm{~nm}$ and the $\alpha$-band shows an absorbance peak at $553 \mathrm{~nm}$ with a shoulder at $559 \mathrm{~nm}$ (Fig. 2b, spectrum 2). Reduction with sodium dithionite (Fig. 2b, spectrum 3) leads to an intensity increase at $559 \mathrm{~nm}$ and the $\gamma$-peak moves to $420 \mathrm{~nm}$. Thus, the visible absorption spectrum of Nar samples shows two different heme moieties, a $c$-type heme with a high electrochemical potential and a $b$-type heme with lower redox potential. The contents of the $b$-type and $c$-type heme moieties in M. hydrocarbonoclasticus $617 \mathrm{Nar}$ were obtained by using standardized methods $[36,37]$. On the basis of a molecular mass of $240 \mathrm{kDa}$ for NarGHI, the heme $b$ and heme $c$ contents were determined to be 1.0 and 0.4 per enzyme molecule, respectively. Extraction of the heme $b$ moiety from Nar and heme quantification in both solubilized extract and apoprotein yielded a heme $b$ to heme $c$ ratio of 2.9 .

UV-vis redox titration

A redox potentiometric titration of the heme moieties detected in M. hydrocarbonoclasticus 617 NarGHI was performed (Fig. 3). The best fit to the experimental data was obtained by considering two noninteracting Nernstian components undergoing a one-electron oxidation-reduction step. The midpoint redox potentials of the hemes were $E_{\mathrm{m} 7.6}=+197 \mathrm{mV}$ (heme $c$ ) and $E_{\mathrm{m} 7.6}=-4.5 \mathrm{mV}$ (heme $b)$. In $E$. coli and $P$. denitrificans enzymes, two different $b$-type hemes $\left(b_{\mathrm{L}}\right.$ and $\left.b_{\mathrm{H}}\right)$ were identified $[11,46,47]$ and 

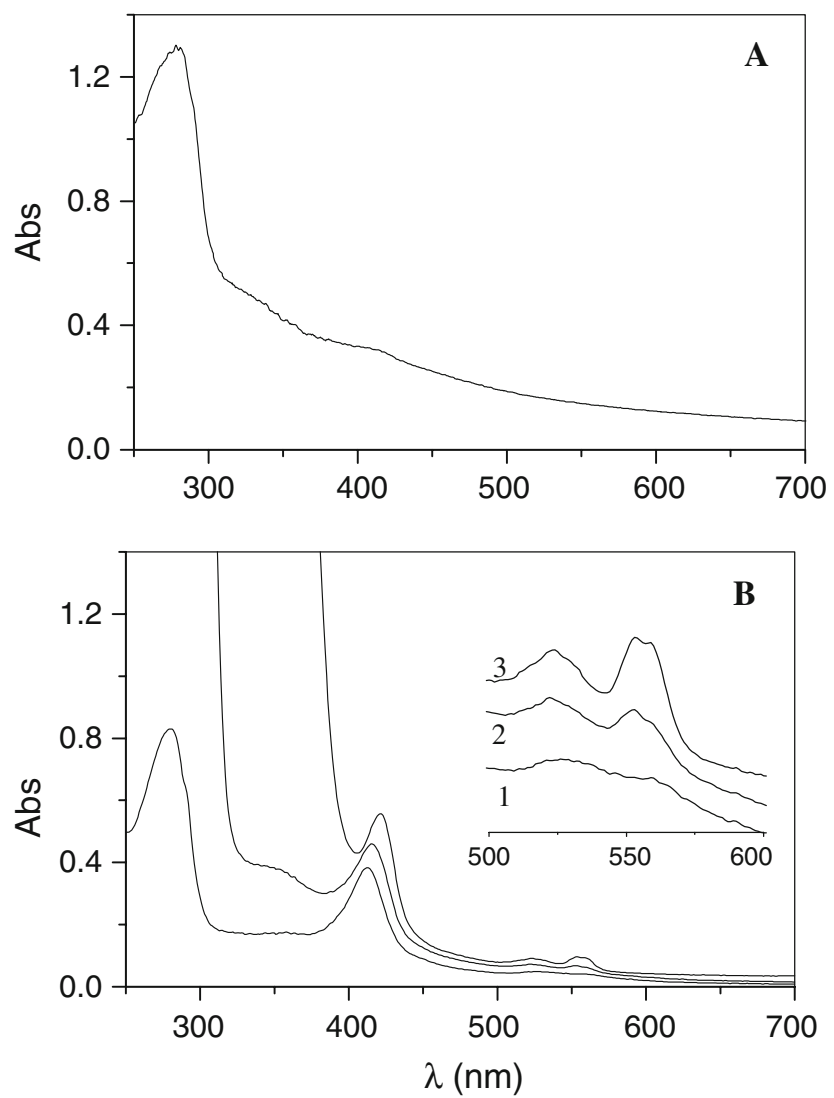

Fig. 2 UV-vis absorption spectra of M. hydrocarbonoclasticus 617 nitrate reductase. a Spectrum of as-isolated (oxidized) NarGH; enzyme $0.4 \mathrm{mg} / \mathrm{mL}$ in $50 \mathrm{mM}$ tris(hydroxymethyl)aminomethane hydrochloride (Tris-HCl) $\mathrm{pH}$ 7.6. b Spectra of NarGHI; enzyme $0.4 \mathrm{mg} / \mathrm{mL}$ in $50 \mathrm{mM}$ Tris- $\mathrm{HCl} \mathrm{pH} 7.6$ with $0.02 \% n$-dodecyl- $\beta$-Dmaltoside (DDM). 1 as-isolated enzyme, 2 ascorbate-reduced enzyme, 3 dithionite-reduced enzyme

their midpoint redox potentials are presented in Table 1 for comparison.

EPR spectroscopy of iron species

The EPR spectrum of as isolated M. hydrocarbonoclasticus 617 NarGH (Fig. 4, spectrum 1) is composed of two signals, one detected only at temperatures below $20 \mathrm{~K}$ and another one detected with no significant changes up to $120 \mathrm{~K}$. The slowly relaxing signal, which is associated with $\mathrm{Mo}(\mathrm{V})$ species, will be discussed below. The signal detected below $20 \mathrm{~K}$ presents a relaxation behavior and $g$ values (Table 2) typical of $[3 \mathrm{Fe}-4 \mathrm{~S}]^{+}$centers [48]. Addition of increasing amounts of oxidant $\left(\mathrm{K}_{3}\left[\mathrm{Fe}(\mathrm{CN})_{6}\right]\right)$ did not show significant changes of signal intensity. In contrast, addition of increasing amounts of dithionite produced a continuous decrease of the signal intensity until its disappearance (not shown). Therefore, the $[3 \mathrm{Fe}-4 \mathrm{~S}]$ center is in a fully oxidized state in the as-isolated form of M. hydrocarbonoclasticus 617 Nar. An EPR signal with

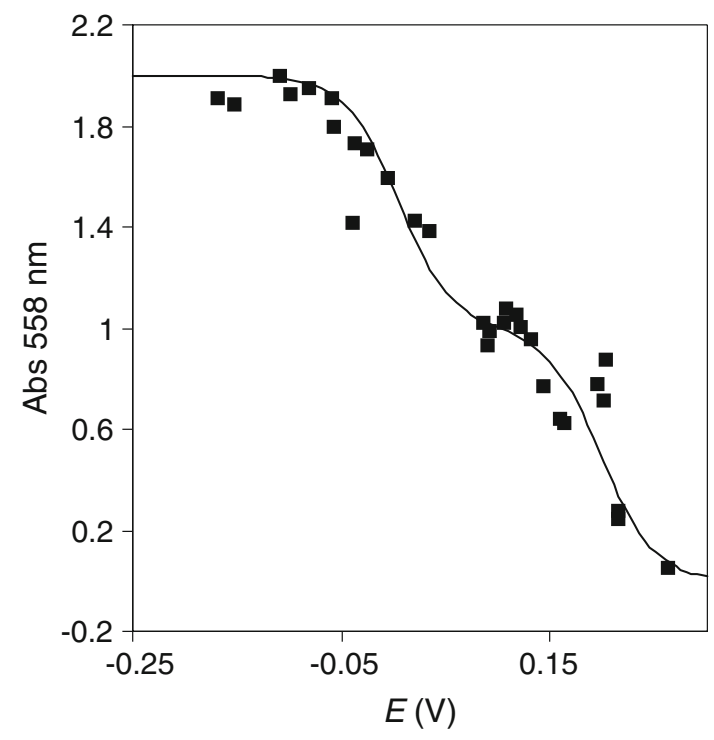

Fig. 3 Redox potentiometric titration curve of the heme moieties detected in $M$. hydrocarbonoclasticus 617 nitrate reductase. Enzyme $2.8 \mathrm{mg} / \mathrm{mL}$ in $50 \mathrm{mM}$ Tris- $\mathrm{HCl} \mathrm{pH} 7.6$ with $0.03 \%$ DDM. Absorbance changes at $558 \mathrm{~nm}$ are plotted versus $E$ (at $\mathrm{pH}$ 7.6). Experimental data were fitted with a nonlinear regression using the Nernst equation for two independent components with $E_{\mathrm{m}, 7.6}$ values of $+197 \mathrm{mV}$ and $-4.5 \mathrm{mV}$

Table 1 Midpoint redox potentials of hemes associated with NarGHI

\begin{tabular}{llll}
\hline Organism & $\mathrm{pH}$ & $E_{\mathrm{m}}(\mathrm{mV})$ \\
\hline Escherichia coli (NarGHI) [46, 47] & 7 & $+17\left(b_{\mathrm{L}}\right)$ & $+122\left(b_{\mathrm{H}}\right)$ \\
Paracoccus denitrificans $[11]$ & 7 & $+95\left(b_{\mathrm{L}}\right)$ & $+210\left(b_{\mathrm{H}}\right)$ \\
Marinobacter hydrocarbonoclasticus 617 & 7.6 & $-4.5(b)$ & $+197(c)$
\end{tabular}

similar properties was observed in the closely related membrane-bound nitrate reductase from E. coli [49] and was assigned to a $[3 \mathrm{Fe}-4 \mathrm{~S}]$ cluster identified as FS4 in the crystal structure reported for E. coli NarGHI [16].

Upon addition of approximately 70 -fold molar excess of sodium dithionite followed by immediate freezing of the sample, the $[3 \mathrm{Fe}-4 \mathrm{~S}]$ signal disappears and is replaced by another set of EPR signals which are detectable below $20 \mathrm{~K}$ as well (Fig. 4, spectrum 3). This redox state of the protein will be identified as the dithionite semireduced state. The spectrum is composed of three overlapping EPR signals with similar relaxation behavior and $g$ values around 2, typical of $[4 \mathrm{Fe}-4 \mathrm{~S}]^{+}$clusters in a low-spin configuration $(S=1 / 2)$. Simulation of this spectrum (Fig. 4, spectrum 4) was achieved by summing spectra 5, 6, and 7 in Fig. 4 in the proportions 0.3:0.7:1 (EPR parameters in Table 2). Two of the components resemble the "minor" and "major" components (Fig. 4, spectra 5 and 6, respectively) of the EPR signal associated with two conformations of a single [4Fe-4S] cluster in E. coli Nar [49] and these signals are identified accordingly in Table 2. The 


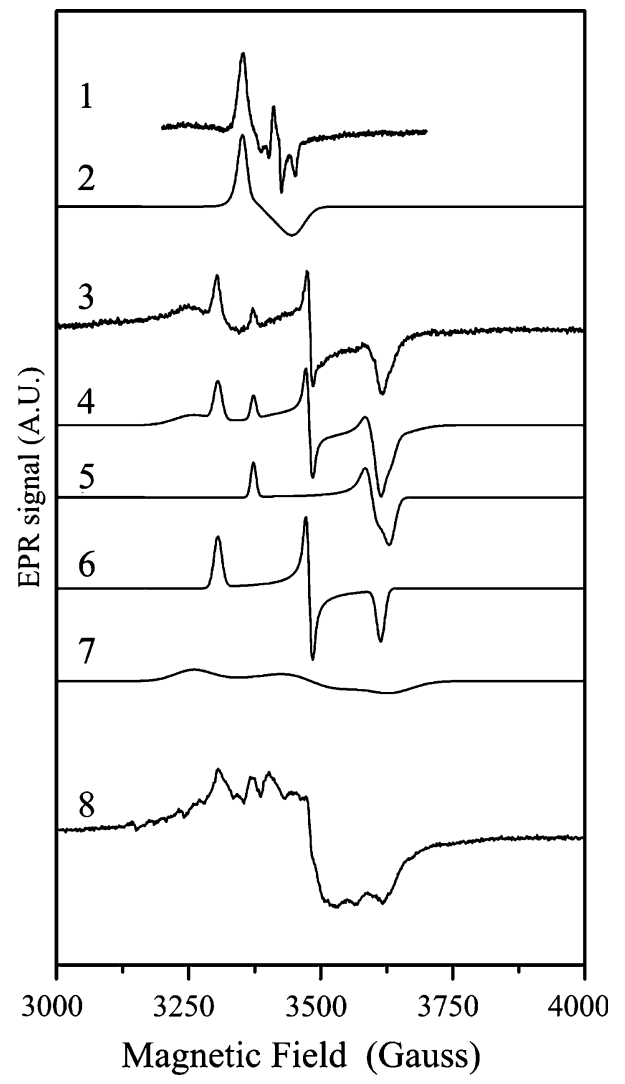

Fig. 4 Electron paramagnetic resonance (EPR) spectra of M. hydrocarbonoclasticus 617 NarGH showing the signals of the iron-sulfur clusters: 1 as-isolated NarGH; 2 computer simulation of the signal due to a $[3 \mathrm{Fe}-4 \mathrm{~S}]^{+}$cluster; 3 dithionite semireduced state; 4 computer simulation of spectrum 3 obtained by adding three distinct components (15\% "minor", 35\% "major," and 50\% "broad"); 5, 6, and 7 computer simulations of minor, major, and broad signals, respectively; 8 dithionite fully reduced state. Simulation parameters are given in Table 2. Experimental conditions were as follows: temperature $10 \mathrm{~K}$, microwave power $0.064 \mathrm{~mW}$, modulation amplitude $4.0 \mathrm{G}$, microwave frequency $9.5 \mathrm{GHz}$

Table 2 Electron paramagnetic resonance $(E P R)$ parameters, determined through simulation, of the signals of the iron-sulfur clusters identified in M. hydrocarbonoclasticus 617 nitrate reductase

\begin{tabular}{lllll}
\hline EPR signals & \multicolumn{3}{l}{$g$ values } & \\
\cline { 2 - 5 } & $g_{1}$ & $g_{2}$ & $g_{3}$ & $g_{\text {av }}$ \\
\hline$[3 \mathrm{Fe}-4 \mathrm{~S}]^{+}$ & 2.020 & 1.999 & 1.965 & 1.995 \\
{$[4 \mathrm{Fe}-4 \mathrm{~S}]^{+}$"major" } & 2.051 & 1.949 & 1.876 & 1.958 \\
{$[4 \mathrm{Fe}-4 \mathrm{~S}]^{+}$"minor" } & 2.010 & 1.885 & 1.871 & 1.922 \\
{$[4 \mathrm{Fe}-4 \mathrm{~S}]^{+}$"broad" } & 2.080 & 1.946 & 1.865 & 1.963 \\
\hline
\end{tabular}

third component found in the M. hydrocarbonoclasticus 617 Nar (Fig. 4, spectrum 7), which is identified as "broad" in Table 2, was not detected in the E. coli enzyme. A progressive reduction of M. hydrocarbonoclasticus 617 Nar was obtained by thawing and incubating this sample under anaerobic conditions. This procedure yielded a less resolved EPR signal whose intensity increases to a maximum after 30-min incubation (Fig. 4, spectrum 8). This ultimate redox state will be identified as the dithionite fully reduced state. The broadening of the EPR lines in spectrum 8 in Fig. 4 may be produced by magnetic couplings between the iron-sulfur clusters, as was previously suggested for the E. coli enzyme [21]. All the EPR signals associated with iron-sulfur clusters were found in the $g \sim 2$ region and no additional signal was detected in the low-field region, unlike in E. coli Nar [25].

The EPR signals obtained in NarGHI are similar to those of NarGH except for the [3Fe-4S] signal, which shows a slight broadening. This suggests that either a heme moiety from the NarI subunit interacts magnetically with the $[3 \mathrm{Fe}-$ $4 \mathrm{~S}$ ] center or that the larger linewidth is produced by conformational changes of the $[3 \mathrm{Fe}-4 \mathrm{~S}]$ region when all subunits are associated.

Spin quantifications performed on the as-isolated state of both NarGH and NarGHI yielded values around 0.3 spins per protein for the $[3 \mathrm{Fe}-4 \mathrm{~S}]$ center. A similar value was obtained for the semireduced state, and 1.1 spins per protein for the fully reduced state. The spin concentration obtained for the as-isolated state of Nar corresponds to the intensity maximum of the EPR signal, which has a main contribution from the $[3 \mathrm{Fe}-4 \mathrm{~S}]$ cluster. This value is lower than that expected for a protein with one $[3 \mathrm{Fe}-4 \mathrm{~S}]$ cluster per protein molecule, suggesting that the protein loses some iron during the purification procedure, as often observed in other closely related molybdenum enzymes.

Although the UV-vis titration data suggest the presence of two distinct heme moieties, the EPR experiment showed a single rhombic signal compatible with a ferric heme [Fe(III), $S=1 / 2]$ in a low-spin configuration $\left(g_{1}=2.986\right.$ and $g_{2}=2.265$ ) (Fig. 5). The $g_{3}$ resonance was not detected, as often occurs.

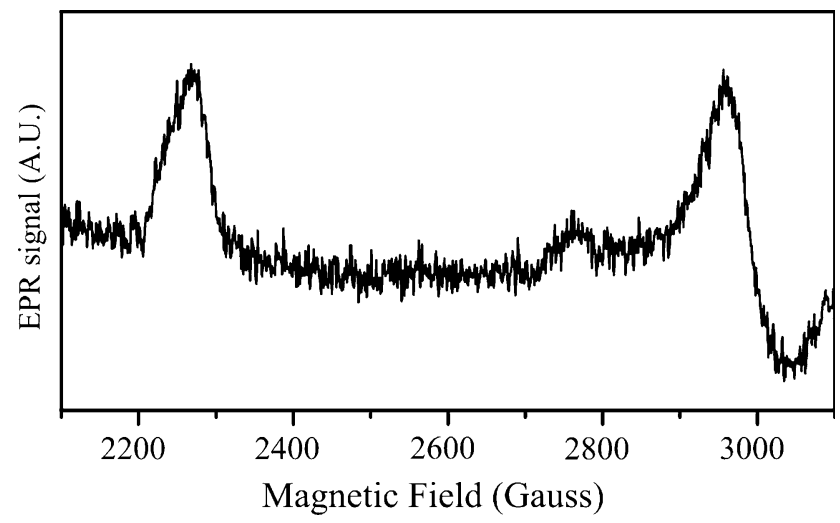

Fig. 5 EPR spectrum of $M$. hydrocarbonoclasticus 617 NarGHI showing the low-spin heme signal. Experimental conditions were as follows: temperature $10 \mathrm{~K}$, microwave power $2 \mathrm{~mW}$, modulation amplitude $4.0 \mathrm{G}$, microwave frequency $9.5 \mathrm{GHz}$ 

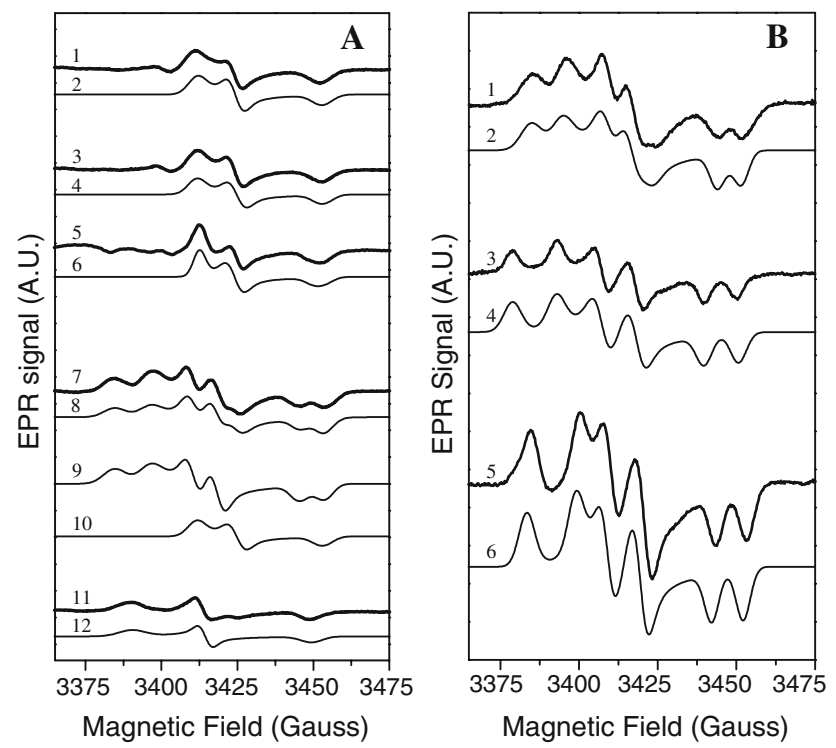

Fig. $6 \mathrm{Mo}(\mathrm{V})$ EPR signals of $M$. hydrocarbonoclasticus $617 \mathrm{NarGHI}$ in the as-isolated, nitrate-complemented, and nitrite-complemented states. a 1 as-isolated enzyme at $\mathrm{pH} 9.0$ in ${ }^{1} \mathrm{H}_{2} \mathrm{O}, 2$ computer simulation of spectrum 1,3 as isolated enzyme at $\mathrm{pH} 7.6$ in ${ }^{1} \mathrm{H}_{2} \mathrm{O}, 4$ computer simulation of spectrum 3,5 as-isolated enzyme at $\mathrm{pH} 7.6$ in ${ }^{2} \mathrm{H}_{2} \mathrm{O}, 6$ computer simulation of spectrum 5,7 as-isolated enzyme at $\mathrm{pH} 6.0$ in ${ }^{1} \mathrm{H}_{2} \mathrm{O}, 8$ computer simulation of spectrum 7 obtained by adding $77 \%$ "low-pH" signal (9) and 23\% "high-pH" signal (10), 11 as-isolated enzyme at $\mathrm{pH} 6.0$ in ${ }^{2} \mathrm{H}_{2} \mathrm{O}, 12$ computer simulation of spectrum 11. Simulation parameters are given in Table 3. b Asisolated enzyme at $\mathrm{pH}$ 6.0. 1 as-isolated Nar (low-pH species), 2 computer simulation of spectrum 1,3100 mM nitrate added to the asisolated enzyme, 4 computer simulation of spectrum 3, $5100 \mathrm{mM}$ nitrite added to the as-isolated enzyme, 6 computer simulation of spectrum 5. Simulation parameters are given in Table 3. Experimental conditions were as follows:temperature $40 \mathrm{~K}$, microwave power $0.63 \mathrm{~mW}$, modulation amplitude $2 \mathrm{G}$, microwave frequency $9.5 \mathrm{GHz}$

\section{EPR spectroscopy of Mo(V)}

$\operatorname{Mo}(\mathrm{V})$ EPR signals of the as-isolated M. hydrocarbonoclasticus 617 NarGHI were recorded at different $\mathrm{pH}$ values (Fig. 6a). These signals were observed up to $120 \mathrm{~K}$ without significant changes and accounted for approximately $10 \%$ of the total molybdenum content. Similar spectra and $\mathrm{pH}$ behavior were observed in NarGH (not shown). These signals are similar to those previously identified in Nars from E. coli [18, 19, 22], P. aeruginosa [9], and Pseudomonas stutzeri $[20]$. The $\mathrm{Mo}(\mathrm{V})$ ion species causing these EPR signals will be termed "low-pH" and "high-pH" according to the nomenclature proposed by Vincent and Bray [18]. The spectrum of the high-pH species was recorded at pH 9 (Fig. 6a, spectrum 1) and pH 7.6 in both water (Fig. 6a, spectrum 3) and deuterated buffer (Fig. 6a, spectrum 5). The "high-pH" signal is nearly axial and the EPR spectrum recorded in a $\mathrm{D}_{2} \mathrm{O}$-exchanged sample has smaller linewidth, indicative of solvent-exchangeable
Table 3 EPR parameters, determined through simulation, of the $\mathrm{Mo}(\mathrm{V})$ signals observed in M. hydrocarbonoclasticus 617 nitrate reductase

\begin{tabular}{|c|c|c|c|c|c|c|c|c|}
\hline \multirow[t]{2}{*}{ Signal } & \multicolumn{4}{|c|}{$g$ values } & \multicolumn{4}{|c|}{$A$ values $(\mathrm{G})$} \\
\hline & $g_{1}$ & $g_{2}$ & $g_{3}$ & $g_{\text {av }}$ & $A_{1}$ & $A_{2}$ & $A_{3}$ & $A_{\mathrm{av}}$ \\
\hline High-pH & 1.987 & 1.980 & 1.963 & 1.977 & 2 & 2 & 3 & 2.3 \\
\hline High-pD & 1.988 & 1.981 & 1.965 & 1.978 & - & - & - & - \\
\hline Low-pH & 1.999 & 1.986 & 1.966 & 1.983 & 12 & 7 & 8 & 9 \\
\hline Low-pD & 2.000 & 1.985 & 1.965 & 1.983 & - & - & - & - \\
\hline Nitrate & 2.002 & 1.987 & 1.968 & 1.986 & 14 & 11 & 11 & 12 \\
\hline Nitrite & 1.999 & 1.986 & 1.967 & 1.984 & 15 & 10 & 10 & 12 \\
\hline Rhombic & 1.996 & 1.982 & 1.958 & 1.979 & - & - & - & - \\
\hline
\end{tabular}

protons weakly coupled to the $\mathrm{Mo}(\mathrm{V})$ ion (EPR parameters in Table 3). This signal is also detected at $\mathrm{pH} 6$ but with lower intensity. Assuming that the "high-pH" signal shows hyperfine coupling to one proton and that the linewidth of the $\mathrm{D}_{2} \mathrm{O}$-exchanged sample corresponds to the uncoupled signal, we estimate the hyperfine coupling of the proton to be $0.3 \mathrm{mT}$.

The spectrum at pH 6 (Fig. 6a, spectrum 7) is composed of the "low-pH" and a small contribution of the "high-pH" signal. The EPR signal associated with the low-pH species exhibits rhombic symmetry as well as hyperfine splitting with a strongly coupled proton $\left[A\left({ }^{1} \mathrm{H}\right)_{\mathrm{av}}=0.9 \mathrm{mT}\right]$. This proton is solvent-exchangeable as observed in the spectrum of the $\mathrm{D}_{2} \mathrm{O}$-exchanged sample (Fig. 6a, spectrum 11). Simulation of the spectrum at $\mathrm{pH} 6.0$ (Fig. 6a, spectrum 8) was obtained with the "low-pH" and "high-pH" signals in a ratio of 1:0.3. The EPR spectrum of the $\mathrm{D}_{2} \mathrm{O}$-exchanged sample also shows both species but with the "high-pH" component in a much lower ratio (Fig. 6a, spectrum 11); hence, its contribution was neglected in the simulation (Fig. 6a, spectrum 12).

Addition of either nitrate or nitrite $(100 \mathrm{mM})$ to the asisolated NarGHI enzyme at pH 6 (Fig. 6b, spectrum 1) leads to the spectra shown in Fig. $6 \mathrm{~b}$ (spectrum 3 for nitrate and spectrum 5 for nitrite). These spectra show $g$ values similar to those found for the low-pH species but with a larger hyperfine splitting of the solvent-exchangeable proton (Table 3). Furthermore, these data indicate that nitrate and nitrite interact in a similar manner with the active site, yielding a $\mathrm{Mo}(\mathrm{V})$ species hereafter called "nitrate/nitrite" derivative. Similar results were obtained at $\mathrm{pH}$ 7.6, indicating that the high-pH species is converted to the nitrate/ nitrite derivative independently of $\mathrm{pH}$. This is in line with previous observations by George et al. [19], who suggested that the presence of these anions displaces the equilibrium towards the low-pH form.

EPR spectra of $\mathrm{Mo}(\mathrm{V})$ species were recorded before and upon nitrate addition (fourfold molar excess with respect to 

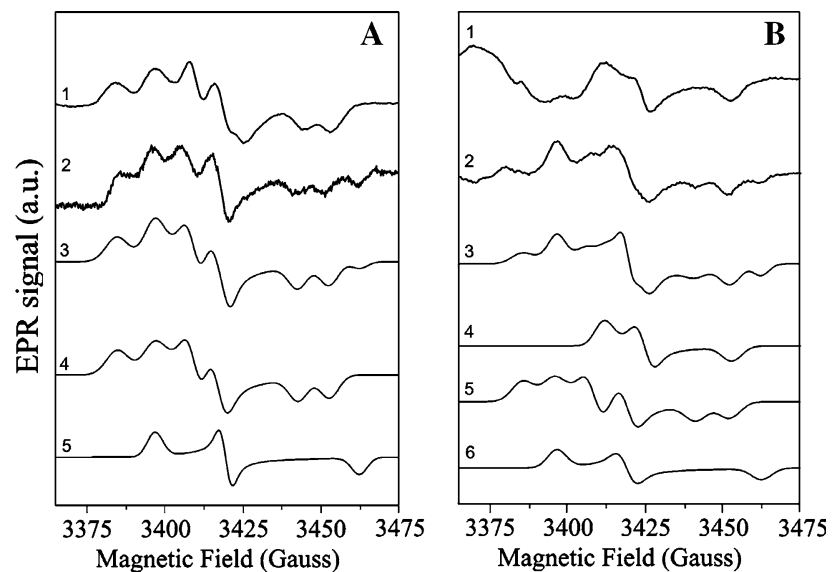

Fig. $7 \mathrm{Mo}(\mathrm{V})$ EPR signals of dithionite-reduced M. hydrocarbonoclasticus 617 NarGHI followed by nitrate addition. a As-isolated enzyme at $\mathrm{pH}$ 6.0. 1 as isolated Nar ("low-pH" signal), 2 sample frozen after $6 \mathrm{~min}$ of nitrate addition to the reduced enzyme, 3 computer simulation of spectrum 2 obtained by summing the "nitrate/ nitrite" derivative signal (simulation in 4) and the rhombic signal (simulation in 5) in a 1:0.5 ratio. b As-isolated enzyme at $\mathrm{pH}$ 7.6. 1 as-isolated Nar ("high-pH" signal), 2 sample frozen upon nitrate addition to the reduced enzyme, 3 computer simulation of spectrum 2 obtained by summing the high-pH signal (simulation in 4 ), the nitrate/ nitrite derivative signal (simulation in 5) and the rhombic signal (simulation in 6) in a 0.4:1:0.65 ratio. Simulation parameters are given in Table 3. Experimental conditions were as follows: temperature $40 \mathrm{~K}$, microwave power $0.63 \mathrm{~mW}$, modulation amplitude $2 \mathrm{G}$, microwave frequency $9.5 \mathrm{GHz}$

dithionite) to dithionite-reduced samples of NarGHI at $\mathrm{pH}$ 6 and 7.6, in both as-isolated and $\mathrm{D}_{2} \mathrm{O}$-exchanged samples (Fig. 7). In the absence of any mediator dye (i.e., methyl viologen) the reaction occurs since nitrite production could also be detected but to a lower extent with respect to that of the normal assay. Nitrite production was also confirmed from an EPR signal at $g \sim 2.03$ (not shown). This signal is supposed to be given by an iron-nitrosyl complex produced by the reaction between the protein with nitric oxide $[50,51]$, which in this case is produced by the reduction of nitrite by excess dithionite. Although the kinetics of the reaction cannot be evaluated in these conditions, the $\mathrm{Mo}(\mathrm{V})$ species obtained under these conditions originate from the conversion of nitrate to nitrite and hence can be considered catalytically relevant as they are produced after reoxidation by nitrate.

The dithionite-reduced samples show no signal associated with $\mathrm{Mo}(\mathrm{V})$ ions, indicating that all the molybdenum is reduced to $\mathrm{Mo}(\mathrm{IV})$, in agreement with the midpoint redox potential of the Mo(V/IV) redox couple reported for other Nars $[45,52]$. The spectra obtained after 6 min of nitrate addition at both $\mathrm{pH}$ values are shown in Fig. 7. The EPR signal at pH 6 (Fig. 7a, spectrum 2) shows two EPRactive species: one corresponds to the nitrate/nitrite derivative species described before, and the second corresponds to a $\mathrm{Mo}(\mathrm{V})$ species that causes a rhombic EPR signal hereafter called "rhombic." This signal (spectrum 5 in Fig. 7a is a simulation of this signal; EPR parameters in Table 3) is identical in both the as-isolated and the $\mathrm{D}_{2} \mathrm{O}$ exchanged sample, suggesting that there are no solventexchangeable protons near the $\mathrm{Mo}(\mathrm{V})$ ion. The rhombic signal species has not been observed in the closely related nitrate reductases from $E$. coli [18], P. aeruginosa [9], $P$. stutzeri [12], and Paracoccus pantotrophus [52]. Spin quantification of the whole signal at $\mathrm{pH} 6$ yields values that are approximately constant with time, with values close to $10 \%$ of the total molybdenum, but the ratio between components is not constant. The rhombic signal is not detected immediately upon nitrate addition but it increases with time, reaching its maximum at $45 \mathrm{~min}$ (Fig. S1, spectrum 1), after which no significant changes were detected. This suggests equilibrium between the species giving rise to the "rhombic" and nitrate/nitrite species. Exposure of this sample to air did not bring about any significant change to the spectrum, confirming that the $\mathrm{Mo}(\mathrm{V})$ species are obtained in nonreducing conditions (Fig. S1, spectrum 2). However, washing the sample with Bis-Tris buffer $\mathrm{pH} 6.0$ led to the disappearance of both components and the appearance of the low-pH $\mathrm{Mo}(\mathrm{V})$ species.

The same experiment conducted at $\mathrm{pH} 7.6$ shows an EPR spectrum with three components (Fig. 7b, spectrum 2): two of them are the "nitrate/nitrite" and the rhombic signals observed at $\mathrm{pH} 6$. The third component is the already described "high-pH" signal (Fig. 6a, spectra 1 and 3 ). As for the sample at $\mathrm{pH} 6$, spin quantification yields values close to $10 \%$ of the total molybdenum and the ratio of the three components varied with time. The three species (high-pH, nitrate/nitrite, and "rhombic") were present in a 0.4:1:0.65 ratio upon nitrate addition, after which the intensity of the "high-pH" signal decreased and became undetectable after $6 \mathrm{~min}$, whereas the ratio of the rhombic and "nitrate/nitrite" signals tends to approximately 0.5 . Washing the sample with Bis-Tris $\mathrm{pH} 7.6$ restored the signal associated with the high-pH species and the experiment with $\mathrm{D}_{2} \mathrm{O}$-exchanged samples confirmed the results obtained at $\mathrm{pH} 6$.

\section{Discussion}

The properties of the NarG and NarH subunits of M. hydrocarbonoclasticus 617 Nar are similar in both heatsolubilized NarGH and detergent-solubilized NarGHI. Nevertheless, the molecular mass difference observed for the NarH subunit between NarGH and NarGHI suggests that the protein is probably more susceptible to proteolysis upon heat treatment, as reported for the closely related E. coli Nar [53]. The NarI subunit was only detected in the 
detergent-solubilized protein. The NarI subunit anchors the NarGH heterodimer to the inner surface of the cytoplasmic membrane and is the quinol oxidation site. UV-vis redox titration of M. hydrocarbonoclasticus 617 Nar showed heme $b$ and heme $c$ moieties, with different redox potentials, whereas $E$. coli Nar has two hemes $b\left(b_{\mathrm{D}}\right.$ and $\left.b_{\mathrm{P}}\right)$ in a low-spin configuration with low and high midpoint redox potentials, respectively $\left[E_{\mathrm{m}}\left(b_{\mathrm{L}}\right)=+17 \mathrm{mV}\right.$ and $E_{\mathrm{m}}\left(b_{\mathrm{H}}\right)=$ $+122 \mathrm{mV}][46,54]$. The presence of a heme $c$ in $M$. hydrocarbonoclasticus 617 Nar would be an unusual feature since most terminal oxidoreductases share the same structural organization with a transmembrane subunit that acts as an anchor and contains two $b$-type hemes [16]. However, the recent sequencing of the Marinobacter aquaeolei VT8 genome may shed light on this matter (GenBank entry CP000514) since this particular bacterium is very likely a strain of $M$. hydrocarbonoclasticus. We may thus assume that the amino acid sequences of NarI from both organisms are closely related. The $M$. aquaeolei VT8 sequence exhibits no cysteine residue that might be involved in heme $c$ binding. On the other hand, the four histidine residues that bind the hemes $b$ in the E. coli sequence [16] are also present in the M. aquaeolei sequence (His56, His66, His188, His206). We must then infer that the $c$-type heme moiety belongs to a tightly bound polypeptide that is copurified with NarGHI and with a molecular mass of approximately $20 \mathrm{kDa}$. The presence of such a cytochrome $c$, although in substoichiometric amount, has also been reported in the Nar isolated from Pseudomonas chlororaphis DSM 50135 [55]. In Thermus thermophilus HB8 a cytochrome $c$ (NarC) is involved in enzyme maturation and in the binding of the $\mathrm{NarGH}$ heterodimer to the membrane [56]. Nevertheless, a narC gene was not found in the nitrate reductase operon of $M$. aquaeolei and the nature and the physiological role of the cytochrome $c$ detected in M. hydrocarbonoclasticus 617 remain to be determined.

The EPR spectra recorded with the as-isolated, semireduced, and fully reduced states of Nar from M. hydrocarbonoclasticus 617 showed EPR signals of iron-sulfur cluster centers similar to those detected in E. coli Nar [18, $22,49,57]$. This suggests that both proteins are closely related, and therefore have a similar cofactor organization. Rothery et al. [25] detected a new EPR signal of a highspin center in $E$. coli Nar $(g=5.023, g=5.556)$, which was assigned to the FS0 cluster of the large subunit. This signal was not detected in M. hydrocarbonoclasticus 617 Nar, but a new EPR signal was observed in the semireduced state. Two possibilities for the assignment for this new signal are proposed: (1) the signal could belong to a low-spin configuration of the FS0 center or (2) this signal could belong to either FS2 or FS3, which are magnetically isolated in this redox state but are not observable in the fully reduced state because of the magnetic interaction between centers.

EPR signals associated with $\mathrm{Mo}(\mathrm{V})$ species in as-isolated M. hydrocarbonoclasticus 617 Nar result from both the low-pH and the high-pH forms (Fig. 6), which are in a $\mathrm{pH}$-dependent equilibrium. At low $\mathrm{pH}$, the EPR results indicate the presence of a solvent-exchangeable proton which should be bound to a ligand of the molybdenum first coordination sphere. This is concluded from the relatively large magnitude of the hyperfine coupling. Taking into consideration the recent crystal structure of $E$. coli Nar [16, 17], our current interpretation is that the molybdenum ion has monodentate coordination by an aspartic acid residue, as observed in the structure of $\mathrm{NarGH}$, and that the sixth position is occupied by an oxygenic species. This form of the enzyme should exhibit an equilibrium between a deprotonated $\mathrm{Mo}(\mathrm{VI})$ species $(\mathrm{Mo}=\mathrm{O})$ and a protonated $\mathrm{Mo}(\mathrm{V})$ species $(\mathrm{Mo}-\mathrm{OH})$. The EPR data taken at high $\mathrm{pH}$ also suggest a similar equilibrium between Mo(VI) and $\mathrm{Mo}(\mathrm{V})$ species as the high-pH form shows also hyperfine coupling, though with a lower strength, to a solventexchangeable proton. However, as explained below, it is important to stress that this equilibrium is not thought to be responsible for the transition between the low-pH and high$\mathrm{pH}$ species. The nature of the $\mathrm{pH}$-dependent interconversion of the active site of Nars has been extensively discussed on the basis of EPR data [18]. Since the EPR data are consistent with a $\mathrm{Mo}(\mathrm{V})$ center ligated by a single hydroxyl group in both high-pH and low-pH forms, George et al. [19] suggested that the proton responsible for the hyperfine coupling to the $\mathrm{Mo}(\mathrm{V})$ ion could not be the same as the one responsible for the acid-base transition. Similar Mo(V) EPR signals have been also detected in the molybdenum-containing enzymes sulfite oxidase and DMSO reductase, and pulsed EPR studies were conducted to investigate the structural details of the $\mathrm{Mo}(\mathrm{V})-\mathrm{OH}$ ligation [58, 59]. These results indicate that a rotation of about $30^{\circ}$ of the $\mathrm{O}-\mathrm{H}$ bond around the $\mathrm{Mo}-\mathrm{O}$ bond may be the reason for the magnitude of the $\mathrm{pH}$-dependent hyperfine coupling. Furthermore, it was suggested that the molybdenum hydroxyl ligand may be involved in a hydrogen bond to some amino acid residue or to a buffer or solvent molecule situated nearby [59]. It is thus plausible that in M. hydrocarbonoclasticus 617 Nar an acid-base transition from a nearby protonable residue, for example, the conserved histidine residue, could trigger orientation changes in the molybdenum hydroxyl ligand, Mo-OH, resulting in a different hyperfine coupling, as has been proposed for E. coli Nar [52].

EPR studies on dithionite-reduced samples oxidized with nitrate showed the presence of the nitrate/nitrite and the "rhombic" species at pH 6, and these two species plus the high-pH species at $\mathrm{pH} 7.6$ (Fig. 7). The data are 
consistent with $\mathrm{Mo}(\mathrm{V})$ species in equilibrium with $\mathrm{Mo}(\mathrm{VI})$ and $\mathrm{Mo}(\mathrm{IV})$ states obtained after nitrite release and hence cannot be associated with intermediates either in the reduction of $\mathrm{Mo}(\mathrm{VI})$ to $\mathrm{Mo}(\mathrm{IV})$ by the external electron donor (dithionite in this case) or the reoxidation of Mo(IV) to $\mathrm{Mo}(\mathrm{VI})$ during the conversion of nitrate to nitrite. Our current interpretation for the nitrate/nitrite derivative is similar to that proposed for the low-pH and high-pH species in which the Mo-OH bond is even more favorably oriented to give larger hyperfine splitting of the solventexchangeable proton. The possibility that this species corresponds to a nitrate (or nitrite) $-\mathrm{Mo}(\mathrm{V})$ adduct is discarded as no evidence of hyperfine coupling with a nitrogen nucleus $(I=1)$ has been detected. The "rhombic" species, on the other hand, could be interpreted in at least two different ways. One could correspond to a molybdenum site in which the carboxylate binding is monodentate and the sixth ligand position is occupied by an oxygenic species, either an oxo group or a hydroxyl with an undetectable hyperfine interaction. The second possibility involves the aspartate residue coordinated in a bidentate fashion. The latter would implicate equilibrium of species having monodentate and bidentate coordination by the aspartate residue. Recent studies in as-isolated NarGH from $P$. pantotrophus detected also a rhombic Mo(V) EPR signal called "high $g$-unsplit" never seen before in a Nar sample. This signal, which has different $g$ values ( $g_{1}=2.007, g_{2}=1.987$, and $\left.g_{3}=1.970\right)$ with respect to the "rhombic" species, was also proposed to correspond to a molybdenum site having bidentate coordination by the aspartate residue [52]. It is evident that neither our work nor the results presented for P. pantotrophus Nar can be conclusive regarding this point. However, this dual behavior in coordination chemistry by side chain carboxylates from aspartic and glutamic acid residues has been evidenced in several system models [60] and is now also obvious from the two crystal structures determined for E. coli Nar [16, 17].

The reaction mechanism suggested for nitrate reductases is still a matter of controversy. Originally, it was thought that a unique reaction mechanism is operative for all nitrate reductases independently of their subclassification (i.e., Nar, assimilatory nitrate reductase, and periplasmic nitrate reductase). The original reaction mechanism, which was mainly based on the crystal structure of the periplasmic nitrate reductase from Desulfovibrio desulfuricans [61], implies the replacement of a sixth coordinating ligand to molybdenum (originally proposed to be a hydroxyl/water molecule) by nitrate, the transfer of two electrons from Mo(IV) to nitrate, and the release of nitrite (see Scheme 1 in [61]). The presence of an aspartate residue coordinated to molybdenum in a bidentate fashion in NarGHI from E. coli [16] suggests that this mechanism can be feasible only if the bidentate coordination is opened and an oxygenic species enters in the sixth coordinating position of the molybdenum atom, as was determined in the crystal structure of NarGH [17]. This hypothesis is supported by the EPR results for both as-isolated and nitrate-reacted $M$. hydrocarbonoclasticus 617 Nar that point to a molybdenum ion coordinated to a hydroxyl/water ligand, which could act as the labile group in a mechanism involving a direct nitrate-molybdenum interaction. Recently, a reevaluation of the crystallographic data of $D$. desulfuricans periplasmic nitrate reductase showed that the molybdenum ligand, originally proposed to be a hydroxyl/water molecule, is a sulfur atom forming a partial disulfide bond with a cysteinethiol group, which suggests a ligand-assisted reaction mechanism instead of the usual redox chemistry based only on the molybdenum atom [62]. These different proposals for the coordination around molybdenum in nitrate reductases suggest distinct processes at molecular level for nitrate reduction, which is the subject of ongoing investigation.

Acknowledgments C.C. and P.J.G. (SFRH/BPD/29812/2006) thank FCT for a fellowship grant. C.D.B. and J.J.G.M. thank SECYT (Argentina) and GRICES (Portugal) for a binational grant. We thank M. Bauzan (LCB-CNRS, Marseille, France) for growing the bacteria used in the present study. This work was supported by project POCI/ QUI/57641/2004 in Portugal and SEPCYT:PICT 2003-06-13872, CONICET PIP 5370, and CAI + D - UNL in Argentina. C.D.B. is a member of CONICET-Argentina.

\section{References}

1. Gonzalez PJ, Correia C, Moura I, Brondino CD, Moura JJ (2006) J Inorg Biochem 100:1015-1023

2. Moura JJ, Brondino CD, Trincao J, Romao MJ (2004) J Biol Inorg Chem 9:791-799

3. Richardson DJ, Berks BC, Russell DA, Spiro S, Taylor CJ (2001) Cell Mol Life Sci 58:165-178

4. Richardson DJ, Watmough NJ (1999) Curr Opin Chem Biol 3:207-219

5. Moreno-Vivian C, Cabello P, Martinez-Luque M, Blasco R, Castillo F (1999) J Bacteriol 181:6573-6584

6. Stolz JF, Basu P (2002) Chembiochem 3:198-206

7. Hille R (1996) Chem Rev 96:2757-2816

8. Clegg RA (1976) Biochem J 153:533-541

9. Godfrey C, Greenwood C, Thomson AJ, Bray RC, George GN (1984) Biochem J 224:601-608

10. Craske A, Ferguson SJ (1986) Eur J Biochem 158:429-436

11. Ballard AL, Ferguson SJ (1988) Eur J Biochem 174:207-212

12. Blümle S, Zumft WG (1991) Biochim Biophys Acta 1057:102108

13. Ketchum PA, Denariaz G, LeGall J, Payne WJ (1991) J Bacteriol 173:2498-2505

14. Philippot L, Clays-Josserand A, Lensi R, Trinsoutreau I, Normand P, Potier P (1997) Biochim Biophys Acta 1350:272-276

15. Jormakka M, Byrne B, Iwata S (2003) FEBS Lett 545:25-30

16. Bertero MG, Rothery RA, Palak M, Hou C, Lim D, Blasco F, Weiner JH, Strynadka NC (2003) Nat Struct Biol 10:681-687 
17. Jormakka M, Richardson D, Byrne B, Iwata S (2004) Structure 12:95-104

18. Vincent SP, Bray RC (1978) Biochem J 171:639-647

19. George GN, Bray RC, Morpeth FF, Boxer DH (1985) Biochem J 227:925-931

20. Hettmann T, Anemuller S, Borcherding H, Mathe L, Steinrucke P, Diekmann S (2003) FEBS Lett 534:143-150

21. Magalon A, Asso M, Guigliarelli B, Rothery RA, Bertrand P, Giordano G, Blasco F (1998) Biochemistry 37:7363-7370

22. Blasco F, Guigliarelli B, Magalon A, Asso M, Giordano G, Rothery RA (2001) Cell Mol Life Sci 58:179-193

23. Guigliarelli B, Magalon A, Asso M, Bertrand P, Frixon C, Giordano G, Blasco F (1996) Biochemistry 35:4828-4836

24. Augier V, Asso M, Guigliarelli B, More C, Bertrand P, Santini CL, Blasco F, Chippaux M, Giordano G (1993) Biochemistry 32:5099-5108

25. Rothery RA, Bertero MG, Cammack R, Palak M, Blasco F, Strynadka NC, Weiner JH (2004) Biochemistry 43:5324-5333

26. Besson S, Carneiro C, Moura JJ, Moura I, Fauque G (1995) Anaerobe 1:219-226

27. Martins CE, Pereira AS, Tavares P, Cordas CM, Folgosa F, Timoteo CG, Sunil N, Huynh BH, Moura JJG, Moura I (2007) In: Springer (ed) 13th International conference on biological inorganic chemistry. Springer, Vienna

28. Prudencio M, Pereira AS, Tavares P, Besson S, Cabrito I, Brown K, Samyn B, Devreese B, Van Beeumen J, Rusnak F, Fauque G, Moura JJ, Tegoni M, Cambillau C, Moura I (2000) Biochemistry 39:3899-3907

29. Baumann P, Baumann L (1981) In: Starr MP, Stolp H, Trüper HG, Balows A, Schlegel HG (eds) The prokaryotes. A handbook on habitats, isolation and identification of bacteria. Springer, New York, pp 1302-1331

30. Starkey RL (1938) Arch Mikrobiol 8:268-304

31. Laemmli UK (1970) Nature 227:680-685

32. Vallejos CE (1983) In: Tansley SD, Orton TJ (eds) Isozymes in plant genetics and breeding, Part A. Elsevier, Amsterdam

33. Goodhew CF, Brown KR, Pettigrew GW (1986) Biochim Biophys Acta 852:288-294

34. Nicholas DJD, Nason A (1957) Methods Enzymol 3:981-984

35. Stoscheck CM (1990) Methods Enzymol 182:50-69

36. Fuhrhop JH, Smith KM (1975) In: Smith KM (ed) Porphyrins and metalloporphyrins. Elsevier, Amsterdam, pp 757-869

37. Berry EA, Trumpower BL (1987) Anal Biochem 161:1-15

38. Fisher DS, Price DC (1964) Clin Chem 10:21-31

39. Kretzer A, Frunzke K, Andreesen JR (1993) J Gen Microbiol 139:2763-2772
40. Gremer L, Meyer O (1996) Eur J Biochem 238:862-866

41. Bonin P, Bertrand JC, Giordano G, Gilewicz M (1987) FEMS Microbiol Lett 48:5-9

42. MacGregor CH, Schnaitman CA, Normansell DE, Hodgins MG (1974) J Biol Chem 249:5321-5327

43. Carlson CA, Ferguson LP, Ingraham JL (1982) J Bacteriol 151:162-171

44. Lund K, DeMoss JA (1976) J Biol Chem 251:2207-2216

45. Anderson LJ, Richardson DJ, Butt JN (2001) Biochemistry 40:11294-11307

46. Hackett NR, Bragg PD (1982) FEMS Microbiol Lett 13:213-217

47. Magalon A, Lemesle-Meunier D, Rothery RA, Frixon C, Weiner JH, Blasco F (1997) J Biol Chem 272:25652-25658. doi: $10.1074 / \mathrm{jbc} .272 .41 .25652$

48. Mouesca JM, Lamotte B (1998) Coord Chem Rev 178180:1573-1614

49. Guigliarelli B, Asso M, More C, Augier V, Blasco F, Pommier J, Giordano G, Bertrand P (1992) Eur J Biochem 207:61-68

50. Kennedy MC, Antholine WE, Beinert H (1997) J Biol Chem 272:20340-20347

51. Boese M, Mordvintcev PI, Vanin AF, Busse R, Mülsch A (1995) J Biol Chem 270:29244-29249

52. Field SJ, Thornton NP, Anderson LJ, Gates AJ, Reilly A, Jepson BJ, Richardson DJ, George SJ, Cheesman MR, Butt JN (2005) Dalton Trans 3580-3586

53. MacGregor CH (1975) J Bacteriol 121:1102-1110

54. Rothery RA, Blasco F, Magalon A, Asso M, Weiner JH (1999) Biochemistry 38:12747-12757

55. Pinho D, Besson S, Silva PJ, de Castro B, Moura I (2005) Biochim Biophys Acta 1723:151-162

56. Zafra O, Cava F, Blasco F, Magalon A, Berenguer J (2005) J Bacteriol 187:3990-3996. doi:10.1128/jb.187.12.3990-3996.2005

57. Magalon A, Rothery RA, Giordano G, Blasco F, Weiner JH (1997) J Bacteriol 179:5037-5045

58. Astashkin AV, Raitsimring AM, Feng C, Johnson JL, Rajagopalan KV, Enemark JH (2002) J Am Chem Soc 124:6109-6118

59. Raitsimring AM, Astashkin AV, Feng C, Enemark JH, Nelson KJ, Rajagopalan KV (2003) J Biol Inorg Chem 8:95-104

60. Brondino CD, Calvo R, Atria AM, Spodine E, Nascimento OR, Pena O (1997) Inorg Chem 36:3183-3189

61. Dias JM, Than ME, Humm A, Huber R, Bourenkov GP, Bartunik HD, Bursakov S, Calvete J, Caldeira J, Carneiro C, Moura JJ, Moura I, Romao MJ (1999) Structure 7:65-79

62. Najmudin S, González PJ, Trincão J, Coelho C, Mukhopadhyay A, Cerqueira NM, Romão CC, Moura I, Moura JJG, Brondino CD, Romão MJ (2008) J Biol Inorg Chem 13:737-753 